Review

\title{
Potential Roles of BMP9 in Liver Fibrosis
}

\section{Jianjun Bi and Shengfang Ge *}

Department of Ophthalmology, Ninth People's Hospital, Shanghai Jiao Tong University School of Medicine, Shanghai 200011, China; E-Mail: jianjun.bi@yahoo.com

* Author to whom correspondence should be addressed; E-Mail: geshengfang@sjtu.edu.cn; Tel.: +86-21-6313-5606; Fax: +86-021-6313-7148.

External Editor: Johannes Haybaeck

Received: 5 September 2014; in revised form: 13 October 2014 / Accepted: 4 November 2014 / Published: 11 November 2014

\begin{abstract}
Liver fibrosis is a common phenomenon that is associated with several pathologies and is characterized by excessive extracellular matrix deposition that leads to progressive liver dysfunction. Bone morphogenetic protein 9 (BMP9) is the most recently discovered member of the BMP family. BMP9 bound with high affinity to activin receptor-like kinase 1 (ALK1) and endoglin in non-parenchymal liver cells. In addition, BMP9 activated $\mathrm{Smad} 1 / \mathrm{Smad} 5 / \mathrm{Smad} 8$ and induced the expression of the target genes inhibitor of differentiation 1 (Id1), hepcidin, Snail and the co-receptor endoglin in liver cells. Although the role of BMP9 in liver fibrosis is currently poorly understood, the presence of BMP9-activated proteins and its target genes have been reported to be associated with liver fibrosis development. This review summarizes the indirect connection between BMP9 and liver fibrosis, with a focus on the BMP9 signaling pathway members ALK1, endoglin, Id1, hepcidin and Snail. The observations on the role of BMP9 in regulating liver fibrosis may help in understanding the pathology mechanisms of liver disease. Furthermore, BMP9 could be served as a potent biomarker and the target of potential therapeutic drugs to treat hepatocytes fibrosis.
\end{abstract}

Keywords: bone morphogenetic protein 9 (BMP9); activin receptor-like kinase 1 (ALK1); endoglin; inhibitor of differentiation 1 (Id1); hepcidin; Snail; liver fibrosis 


\section{Introduction}

Liver fibrosis is a pathological process in which excessive precipitation of diffusive liver extracellular matrix (ECM) occurs as a result of intrahepatic connective tissue dysplasia caused by a variety of pathogenic factors. Many chronic liver diseases, such as viral hepatitis, alcoholic liver disease, fatty liver, and autoimmune diseases, can cause fibrosis $[1,2]$. In response to various factors that may cause liver damage, liver cells undergo degeneration, necrosis and apoptosis. In combination with liver tissue inflammation, these pathological effects lead to the release of inflammatory cytokines and chemical neurotransmitters. These factors act on hepatic stellate cells (HSCs), inducing the proliferation and activation/transformation of these cells into myofibroblasts, which subsequently synthesize large amounts of ECM components, such as collagen and proteoglycans. In addition, activated HSCs also produce substances that inhibit protease activity, thereby increasing ECM deposition in the liver. As a result of matrix deposition in the liver, fibrosis is formed [3-5]. To date, a variety of signal transduction pathways and cytokines have been demonstrated to regulate the development of liver fibrosis, including transforming growth factor- $\beta 1$ (TGF- $\beta 1$ ), bone morphogenetic protein 7 (BMP7), and Smad [6-8].

Figure 1. Bone morphogenetic protein 9 (BMP9) biosynthesis. BMP9 is synthesized as a 429 amino acids (aa) precursor protein (Pre-pro-BMP9) composed of a 22 aa signal peptide, a 297 aa prodomain and a 110 aa mature protein. The pre-pro-BMP9 then homodimerizes and is subsequently cleaved to generates two active forms: The short mature BMP9 (25 kDa) and the complexed form $(100 \mathrm{kDa})$.

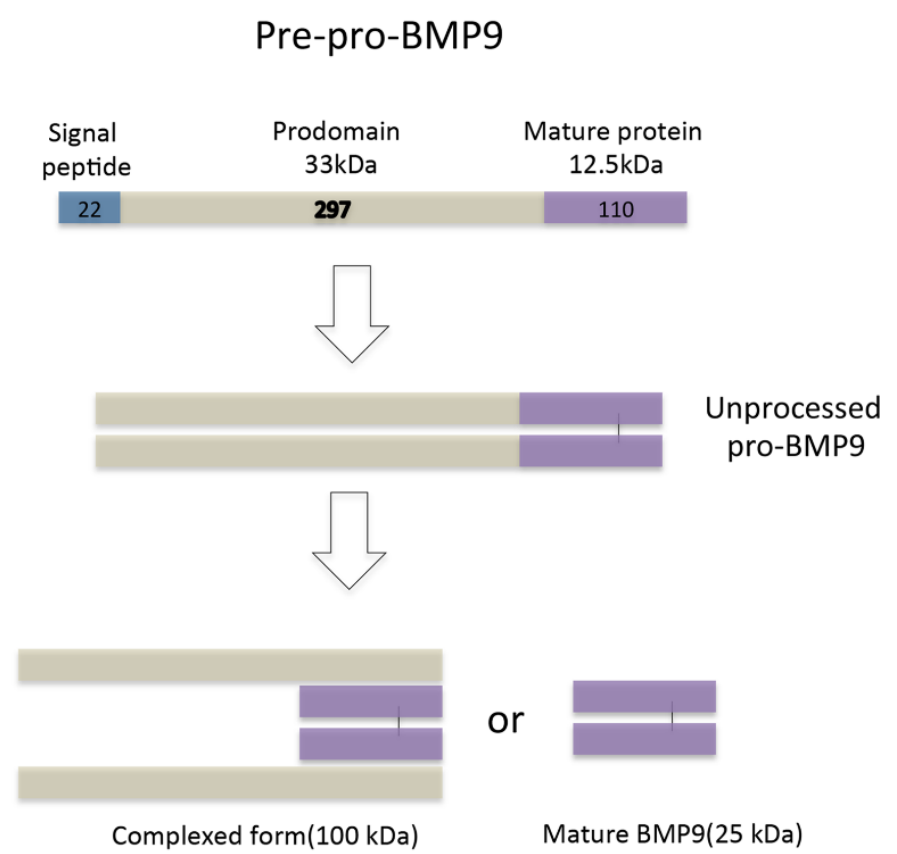

Bone morphogenetic protein 9 (BMP9), which is also known as growth differentiation factor 2 (GDF2), belongs to the TGF- $\beta$ superfamily $[9,10]$. In mammals, the TGF- $\beta$ superfamily consists of more than 30 ligands, including BMPs, TGF- $\beta$ subfamily members, activins, seven type I receptors (ALK1-7), and five type II receptors (ActRIIA, ActRIIB, BMPRII, TGF_RII, and AMHRII), as well as several o-receptors and accessory proteins such as endoglin and betaglycan [11]. BMP9 is specifically expressed 
in liver tissue [12] as a precursor protein (pre-pro-BMP9) composed of 429 amino acids (aa) that include a 22 aa signal peptide, a $33 \mathrm{kDa}$ prodomain and a $12.5 \mathrm{kDa}$ mature protein. The pre-pro-BMP9 is then cleaved by serine endoproteases, leading to a short dimeric mature form of $25 \mathrm{kDa}$ and the prodomain, which can remain noncovalently associated with the mature short form, giving a size of approximately $100 \mathrm{kDa}$ (Figure 1) [13]. BMP9 was initially identified in a murine cDNA library, secreting in both autocrine and paracrine ways [14]. BMP9 regulates several biological functions, including iron ion balance [15], cartilage formation [16], angiogenesis [17,18] and the differentiation of neurons [19], glucose and lipid metabolism [20] When BMP9 acts on liver stellate cells, the regeneration of parenchymal hepatic cells is promoted [12,14].

Little is known about a direct link between BMP9 and liver fibrosis. Fully understanding the relationships between BMP9 signal transduction pathways and multiple target molecules during the fibrotic progression could provide insight into the potential role of BMP9 in liver fibrosis.

\section{Bone Morphogenetic Protein 9 (BMP9) Receptors and Signal Transduction Pathways in Hepatocytes}

Secreted BMPs transduce their signal via a combination of transmembrane serine/threonine kinase receptors, which are comprised of two subtypes: Subtype I (ALK1, ALK2, ALK3 and ALK6) and subtype-II (BMPRII, ActRIIA and ActRIIB). Five membrane BMP9 receptors have been recently reported, these receptors include ALK1, ALK2, BMPR-II, ActRII-B and the co-receptor endoglin [17]. In endothelial cells (ECs), BMP9 binds with high affinity to ALK1 and the co-receptor endoglin. It can also bind to ALK2, BMPRII and ActRII with weak affinity [17,21]. Notably, Townson SA et al. reported that BMP9 binds to ALK1 and ActRIIB with high affinity (KD = 30 pmol) in Biacore experiments, which is significantly higher than those of BMPRII $(\mathrm{KD}=2113$ pmol $)$ and ActRIIA $(\mathrm{KD}=10,370 \mathrm{pmol})[22]$. The mode of BMP9-receptor interaction is different from other BMPs and TGF- $\beta$ members, other BMPs often binding first to the subtype I receptors while members of TGF- $\beta$ subfamily bind first to the subtype I receptors. These factors activate different signal transduction molecules to mediate the hepatic fibrosis process [23]. The affinity of BMP9 for its receptors on different cell types varies. In cells that do not express ALK1, such as parenchymal hepatic cells, the functions of BMP9 are mediated by the high affinities for ActRII or ALK2 [17,24,25].

Under physiological conditions, BMP9 is primarily expressed and secreted by the liver $[12,14,26]$. Expression of the BMP9 receptors ALK1, ALK2, ActRII and BMPRII is observed in liver tissue, primary liver cells and liver cancer cell lines [27-30], indicating that BMP9 may play biological roles in liver cells through these receptors. However, the exact mechanism of action and the biological effects of BMP9 are yet to be studied.

The key aspects of the development of liver fibrosis are the activation of non-parenchymal hepatic cells and the imbalance of the cellular functions. Previous experiments demonstrated that HSCs [31], bile duct ECs and Kupffer cells [14,32] primarily express the type I receptor of ALK1, which can bind to BMP9 and subsequently activate intracellular signaling pathways [24].

BMP9 regulates target gene transcription and expression primarily through the Smad pathway [29]. Smad proteins are substrates of BMP receptors such as ALK1. These proteins play an important role in transducing the signal from BMP receptors to target genes within the cell nucleus. The binding of BMP9 
to cell membrane receptors induces the formation of a heterologous membrane receptor complex. Activated receptors bind to Smad1, Smad5, Smad8 and phosphorylate these proteins. The activated Smad proteins form a complex, translocate to the nucleus, and bind to a Smad-responsive element in the target gene, eventually inducing the up-regulation of endoglin RNA and the target proteins in ECs (Figure 2) [15,17,31,33].

Figure 2. BMP signaling pathway. BMP9 signal transduction in liver cells: BMP9 signal via the type I receptor (ALK1, ALK2) and type II receptor (BMPR2, ActRII) in liver cells. The co-receptor endoglin can modulate signaling via the type II and type I receptors. Activated receptors bind to Smad1, Smad5, Smad8 and phosphorylate the proteins, the activate complex translocates to the nucleus, and bind to Smad-responsive element in the target gene and inducing gene expression.

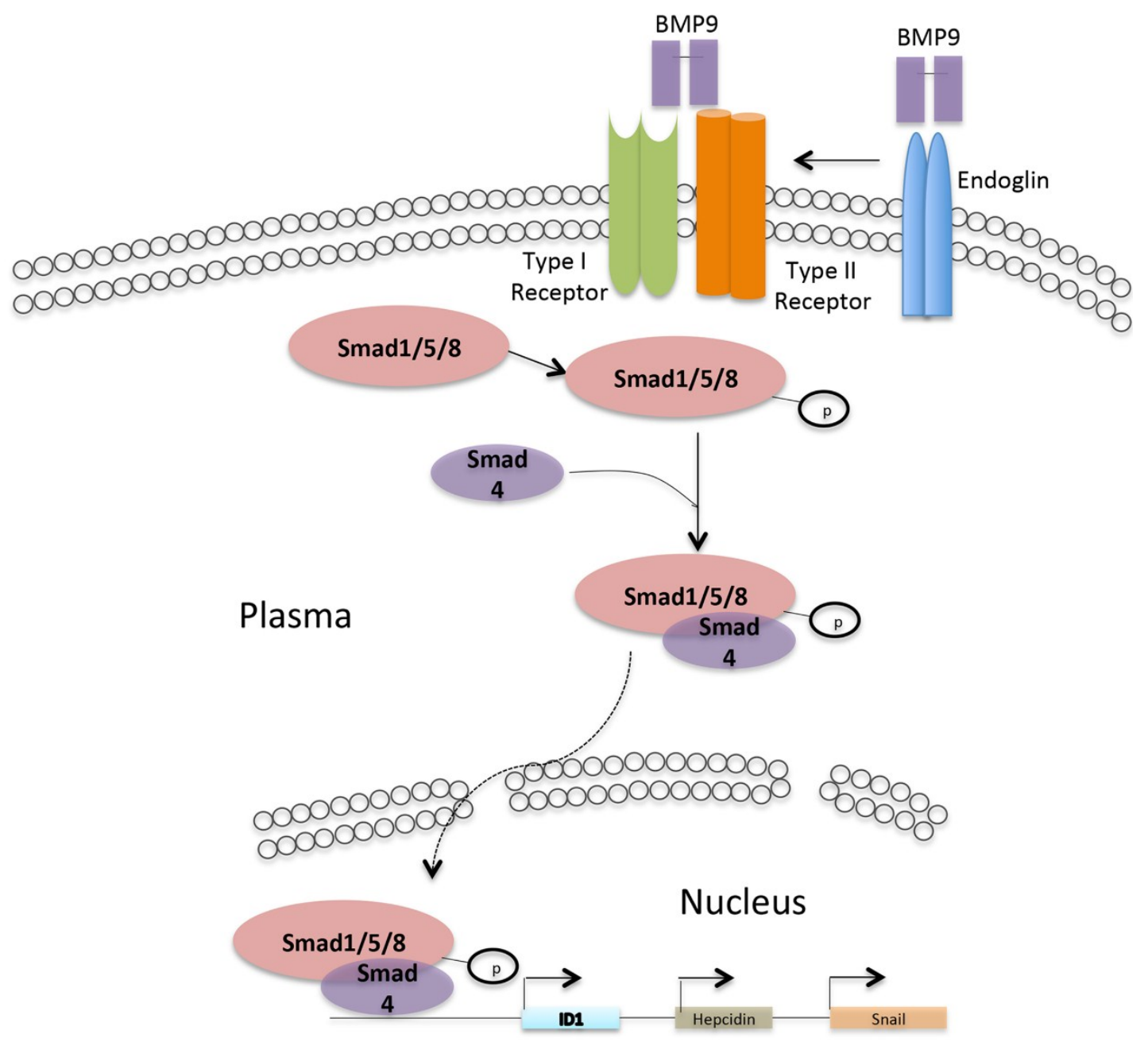

Other studies have demonstrated that BMP9 can be functioned by phosphorylating Smad2 and Smad3, thus resembling the activation of TGF- $\beta$ subfamily factors. However, this phenomenon has only been reported to occur in some endothelial cell lines [17,34,35]. No similar observations have been reported in liver cells [24].

Various interactions have been reported between different intracellular signal transduction pathways. Signaling molecules in one pathway may affect or regulate other signaling pathways. One well-known 
example is the regulation of Smad phosphorylation by the Ras/mitogen-activated protein kinase (MAPK) pathway. In recent years, studies used different protein kinase inhibitors to demonstrate that c-Jun $N$-terminal kinases (JNKs), p38 and ERK1/2 are also involved in BMP9-induced osteogenesis and differentiation of mesenchymal stem cells. The inhibition of MAPK can result in reduced BMP9 function [36-38]. Thus, we can postulate that after the Ras/MAPK pathway is activated, activated ERK1/2 can phosphorylate the Smad proteins, regulating the accumulation of these proteins in the nucleus and thereby regulating Smad signal transduction. To date, these non-Smad pathways have rarely been studied in liver cells [24].

\section{Relationship between Activin Receptor-Like Kinase 1 (ALK1) and Liver Fibrosis}

The activation and functional changes of liver non-parenchymal cells are important pathological processes associated with liver fibrosis. The main BMP9 receptor in liver non-parenchymal cells is ALK1 [24,31]. During liver fibrosis, ligand-activated ALK1 activates the target gene Id1 through the Smad1 pathway, thereby inducing HSCs to differentiate into fibroblasts, which produce ECM proteins $[39,40]$. In other fibrotic diseases, such as scleroderma, research has demonstrated an abnormal overexpression of ALK1 and its associated activated proteins [41,42].

Treating HSCs with the herbal compound 861 (Cpd 861) results in the suppression of ALK1 expression, leading to decreases in key ECM components, such as collagen type III and $\alpha$ SMA, as well as increased expression of matrix metalloproteinase1 (MMP1). Thus, Cpd 861 exhibits anti-fibrotic activity $[43,44]$.

The process epithelial to mesenchymal transition (EMT) leads to pathological changes in tissues. This process occurs in response to specific cytokines. Li et al. proposed that EMT may be an important mechanism of liver fibrosis [29,30,45]. They demonstrated that the BMP9/ALK1/Smad1 signaling pathway is involved in the EMT of liver cancer cells. The over-expression of ALK1 leads to up-regulation of the mesenchymal cell marker vimentin and down-regulation of E-cadherin [29].

\section{Relationship between Endoglin and Liver Fibrosis}

Endoglin (CD105) is a co-receptor of TGF- $\beta$ and BMPs $[46,47]$. It cannot bind ligand on its own but does bind BMP9 in the presence of type I or type II signaling receptors. Endoglin is a transmembrane protein with large extracellular domains and serine/threonine-rich cytoplasmic regions. Phosphorylation of human endoglin occurs in endothelial cells and mouse fibroblasts. The phosphor-activation status of this co-receptor is regulated by cell surface receptors, including ALK5, ALK1 and Type II receptors, and can also mediate a feedback loop in response to the phosphorylation of ALK5 and type II receptors [48,49]. Endoglin is expressed in ECs, epithelial cells, fibroblasts and HSCs, modulates TGF- $\beta$ signal transduction by inhibiting the ALK5-Smad2/3 pathway and enhancing the ALK1-Smad1/5 pathway [50-53].

An immunoprecipitation assay with ${ }^{125}$ I labeled BMP9 and endoglin cDNA-transfected cells revealed a high affinity for BMP9 and endoglin [17]. Endoglin exerts a remarkable regulatory effect on BMP signaling by regulating Smad phosphorylation; it plays an important role in liver fibrosis. Previous experiments demonstrate that during liver fibrosis induced by different causes, the circulating endoglin level is significantly increased. These results suggest that endoglin is involved in hepatitis $\mathrm{C}$ virus 
(HCV)-induced liver fibrosis and can serve as a prognostic biomarker for patients with biliary atresia (BA) liver injury $[54,55]$. Results reported by Meurer SK et al. demonstrate that in murine liver stellate cells, endoglin up-regulates ERK1/2 phosphorylation levels by activating Smad1/5/8. In addition, endoglin increases the expression levels of vimentin, which is an important component of ECM and circulation, and is a connective tissue growth factor [56].

\section{Relationship between the BMP9 Target Gene Id1 and Liver Fibrosis}

Previous experiments using HepG2 liver cell lines and cultured primary cells demonstrate that BMP9 significantly induces Id1 expression [24,57]. As a target gene of BMP9, Id1 plays important roles in the transformation of HSCs into fibroblasts and in the EMT of HSCs [58]. Eliza Wiercinska et al. analyze the Smad7-dependent mRNA profile in HSCs cells. They report ectopic Smad7 expression in HSCs with strongly reduced Id1 mRNA and protein expression. They also found that the deletion of Id1 in HSCs impairs the synthesis of $\alpha$ SMA, suggesting that Id1 has a vital function during fibrosis [31]. The results reported by Ding BS et al. also suggest that acute injury of sinusoidal ECs induces high expression of the transcription factor Id1, leading to liver regeneration [59]. Matsuda, et al. conduct a study with 112 patients and demonstrate that among patients with liver cirrhosis, an increase in Id1 expression is an independent risk factor for the occurrence of hepatocellular carcinoma (HCC). Id1 plays key roles in the early stage of liver cancer development and can be used as a high-risk marker for predicting whether a patient with cirrhosis will eventually develop HCC [60]. A key phenomenon that occurs during hepatic fibrosis is the activation of HSCs to become fibroblasts. In this process, the basic helix-loop-helix (bHLH) transcription factor Id1 plays an important role. The activation of HSCs is accompanied by reduced expression of the inhibitory Id1. The molecular mechanisms that underlie the effects of the Id1 protein on HSC activation and liver fibrosis remain unclear [61].

\section{Relationship between the BMP9 Target Gene Hepcidin and Liver Fibrosis}

In liver cells, another important target gene of BMP9 is hepcidin, which is a cysteine-rich antimicrobial polypeptide. BMP9 can up-regulate hepcidin expression [15]. A significant effect of hepcidin is the inhibition of the absorption and recycling of iron. In the clinic, iron deposition accompanies the hepatic fibrosis and cirrhosis that are caused by a variety of advanced stage diseases [62-64]. In patients with chronic hepatitis $\mathrm{C}$, iron deposition in the liver may cause oxidative stress damage and induce apoptosis, thereby contributing to liver fibrosis. Patients with chronic liver disease tend to have disorders related to hepcidin expression and hepatic iron deposition. These effects may ultimately contribute to liver fibrosis $[65,66]$. Hepcidin expression and the concentration of serum prohepcidin are significantly reduced in patients with chronic hepatitis $C$. These phenomena are more significant in patients with cirrhosis and are negatively correlated with serum ferritin levels and liver iron content [67-69]. Sebastiani $\mathrm{G}$ et al. used the hemojuvelin $\mathrm{Hjv}^{-/-}$mouse model to study the effects of iron overload on liver fibrosis. They found that the deletion of the Hjv gene leads to the deposition of iron ions and, consequently, promotes liver fibrosis [70]. It is reasonable to postulate that iron deposition in the liver may occur due to the reduction of hepcidin. Thus, hepcidin may be a therapeutic target or a biological marker of iron deposition-associated liver fibrosis. It is possible that hepcidin and BMP9 use different mechanisms to induce liver fibrosis. 


\section{Relationship between the BMP9 Target Gene Snail and Liver Fibrosis}

Snail is a key regulator of EMT. BMP9 can induce the expression of Snail in liver cancer cells [29]. When inhibiting Snail-1 activity with the Snail inhibitor, pro-fibrotic genes, such as connective tissue growth factor (CTGF), collagen I and TGF-1, are down-regulated. These effects result in the inhibition of fibrosis and indicate that Snail is involved in fibrosis [71]. Researchers studied the EMT process by inhibiting Snail and reported that inhibiting Snail can inhibit EMT [72]; this finding suggests that the inhibition of Snail can be used to reduce the progression of liver fibrosis.

\section{Conclusions}

Although few studies have investigated the direct correlation between BMP9 and liver fibrosis, the available results demonstrate that BMP9 is primarily expressed in liver cells and acted in both autocrine and paracrine manners. This protein is widely involved in the functions of many receptors linked to liver fibrosis-promoting, the action of downstream signaling molecules and the expression of target genes in liver cells. Our studies and many others postulate that BMP9 is one of factors that may induce liver fibrosis by potentially regulating the process of fibrosis.

\section{Acknowledgments}

This work was supported by the National Natural Science Foundation of China grant (81172323, U1432117), the Science and Technology Commission of Shanghai (13JC1406202).

\section{Author Contributions}

Jianjun Bi drafted, Shengfang Ge revised and give modification of the review.

\section{Conflicts of Interest}

The authors declare no conflict of interest.

\section{References}

1. Ramachandran, P.; Iredale, J.P. Liver fibrosis: A bidirectional model of fibrogenesis and resolution. QJM 2012, 105, 813-817.

2. Mastroianni, C.M.; Lichtner, M.; Mascia, C.; Zuccala, P.; Vullo, V. Molecular mechanisms of liver fibrosis in HIV/HCV coinfection. Int. J. Mol. Sci. 2014, 15, 9184-9208.

3. Mallat, A.; Lotersztajn, S. Cellular mechanisms of tissue fibrosis. 5. Novel insights into liver fibrosis. Am. J. Physiol. Cell Physiol. 2013, 305, C789-C799.

4. Pinzani, M.; Macias-Barragan, J. Update on the pathophysiology of liver fibrosis. Expert Rev. Gastroenterol. Hepatol. 2010, 4, 459-472.

5. Su, T.H.; Kao, J.H.; Liu, C.J. Molecular mechanism and treatment of viral hepatitis-related liver fibrosis. Int. J. Mol. Sci. 2014, 15, 10578-10604.

6. Xu, R.; Zhang, Z.; Wang, F.S. Liver fibrosis: Mechanisms of immune-mediated liver injury. Cell. Mol. Immunol. 2012, 9, 296-301. 
7. Povero, D.; Busletta, C.; Novo, E.; di Bonzo, L.V.; Cannito, S.; Paternostro, C.; Parola, M. Liver fibrosis: A dynamic and potentially reversible process. Histol. Histopathol. 2010, 25, 1075-1091.

8. Gressner, O.A.; Rizk, M.S.; Kovalenko, E.; Weiskirchen, R.; Gressner, A.M. Changing the pathogenetic roadmap of liver fibrosis? Where did it start; where will it go? J. Gastroenterol. Hepatol. 2008, 23, 1024-1035.

9. Lamplot, J.D.; Qin, J.; Nan, G.; Wang, J.; Liu, X.; Yin, L.; Tomal, J.; Li, R.; Shui, W.; Zhang, H.; et al. BMP9 signaling in stem cell differentiation and osteogenesis. Am. J. Stem Cells 2013, 2, $1-21$.

10. Brown, M.A.; Zhao, Q.; Baker, K.A.; Naik, C.; Chen, C.; Pukac, L.; Singh, M.; Tsareva, T.; Parice, Y.; Mahoney, A.; et al. Crystal structure of BMP9 and functional interactions with pro-region and receptors. J. Biol. Chem. 2005, 280, 25111-25118.

11. Ten Dijke, P.; Arthur, H.M. Extracellular control of TGF- $\beta$ signalling in vascular development and disease. Nat. Rev. Mol. Cell Biol. 2007, 8, 857-869.

12. Song, J.J.; Celeste, A.J.; Kong, F.M.; Jirtle, R.L.; Rosen, V.; Thies, R.S. Bone morphogenetic protein-9 binds to liver cells and stimulates proliferation. Endocrinology 1995, 136, 4293-4297.

13. Bidart, M.; Ricard, N.; Levet, S.; Samson, M.; Mallet, C.; David, L.; Subileau, M.; Tillet, E.; Feige, J.J.; Bailly, S. BMP9 is produced by hepatocytes and circulates mainly in an active mature form complexed to its prodomain. Cell. Mol. Life Sci. 2012, 69, 313-324.

14. Miller, A.F.; Harvey, S.A.; Thies, R.S.; Olson, M.S. Bone morphogenetic protein-9. An autocrine/ paracrine cytokine in the liver. J. Biol. Chem. 2000, 275, 17937-17945.

15. Truksa, J.; Peng, H.; Lee, P.; Beutler, E. Bone morphogenetic proteins 2, 4, and 9 stimulate murine hepcidin 1 expression independently of Hfe, transferrin receptor 2 (Tfr2), and IL-6. Proc. Natl. Acad. Sci. USA 2006, 103, 10289-10293.

16. Kang, Q.; Sun, M.H.; Cheng, H.; Peng, Y.; Montag, A.G.; Deyrup, A.T.; Jiang, W.; Luu, H.H.; Luo, J.; Szatkowski, J.P.; et al. Characterization of the distinct orthotopic bone-forming activity of 14 BMPs using recombinant adenovirus-mediated gene delivery. Gene Ther. 2004, 11, 1312-1320.

17. Scharpfenecker, M.; van Dinther, M.; Liu, Z.; van Bezooijen, R.L.; Zhao, Q.; Pukac, L.; Lowik, C.W.; ten Dijke, P. BMP9 signals via ALK1 and inhibits bFGF-induced endothelial cell proliferation and VEGF-stimulated angiogenesis. J. Cell Sci. 2007, 120, 964-972.

18. David, L.; Mallet, C.; Keramidas, M.; Lamande, N.; Gasc, J.M.; Dupuis-Girod, S.; Plauchu, H.; Feige, J.J.; Bailly, S. Bone morphogenetic protein-9 is a circulating vascular quiescence factor. Circ. Res. 2008, 102, 914-922.

19. Schnitzler, A.C.; Mellott, T.J.; Lopez-Coviella, I.; Tallini, Y.N.; Kotlikoff, M.I.; Follettie, M.T.; Blusztajn, J.K. BMP9 (bone morphogenetic protein-9) induces NGF as an autocrine/paracrine cholinergic trophic factor in developing basal forebrain neurons. J. Neurosci. 2010, 30, 8221-8228.

20. Chen, C.; Grzegorzewski, K.J.; Barash, S.; Zhao, Q.; Schneider, H.; Wang, Q.; Singh, M.; Pukac, L.; Bell, A.C.; Duan, R.; et al. An integrated functional genomics screening program reveals a role for BMP9 in glucose homeostasis. Nat. Biotechnol. 2003, 21, 294-301.

21. David, L.; Mallet, C.; Mazerbourg, S.; Feige, J.J.; Bailly, S. Identification of BMP9 and BMP10 as functional activators of the orphan activin receptor-like kinase 1 (ALK1) in endothelial cells. Blood 2007, 109, 1953-1961. 
22. Townson, S.A.; Martinez-Hackert, E.; Greppi, C.; Lowden, P.; Sako, D.; Liu, J.; Ucran, J.A.; Liharska, K.; Underwood, K.W.; Seehra, J.; et al. Specificity and structure of a high affinity activin receptor-like kinase 1 (ALK1) signaling complex. J. Biol. Chem. 2012, 287, 27313-27325.

23. Mueller, T.D.; Nickel, J. Promiscuity and specificity in BMP receptor activation. FEBS Lett. 2012, 586, 1846-1859.

24. Herrera, B.; Dooley, S.; Breitkopf-Heinlein, K. Potential roles of bone morphogenetic protein (BMP)-9 in human liver diseases. Int. J. Mol. Sci. 2014, 15, 5199-5220.

25. Herrera, B.; van Dinther, M.; ten Dijke, P.; Inman, G.J. Autocrine bone morphogenetic protein-9 signals through activin receptor-like kinase-2/Smad1/Smad4 to promote ovarian cancer cell proliferation. Cancer Res. 2009, 69, 9254-9262.

26. Popov, Y.; Patsenker, E.; Stickel, F.; Zaks, J.; Bhaskar, K.R.; Niedobitek, G.; Kolb, A.; Friess, H.; Schuppan, D. Integrin $\alpha v \beta 6$ is a marker of the progression of biliary and portal liver fibrosis and a novel target for antifibrotic therapies. J. Hepatol. 2008, 48, 453-464.

27. Arndt, S.; Maegdefrau, U.; Dorn, C.; Schardt, K.; Hellerbrand, C.; Bosserhoff, A.K. Iron-induced expression of bone morphogenic protein 6 in intestinal cells is the main regulator of hepatic hepcidin expression in vivo. Gastroenterology 2010, 138, 372-382.

28. Xia, Y.; Babitt, J.L.; Sidis, Y.; Chung, R.T.; Lin, H.Y. Hemojuvelin regulates hepcidin expression via a selective subset of BMP ligands and receptors independently of neogenin. Blood 2008, 111, 5195-5204.

29. Li, Q.; Gu, X.; Weng, H.; Ghafoory, S.; Liu, Y.; Feng, T.; Dzieran, J.; Li, L.; Ilkavets, I.; Kruithof-de Julio, M.; et al. Bone morphogenetic protein-9 induces epithelial to mesenchymal transition in hepatocellular carcinoma cells. Cancer Sci. 2013, 104, 398-408.

30. Zilberberg, L.; ten Dijke, P.; Sakai, L.Y.; Rifkin, D.B. A rapid and sensitive bioassay to measure bone morphogenetic protein activity. BMC Cell Biol. 2007, 8, 41.

31. Wiercinska, E.; Wickert, L.; Denecke, B.; Said, H.M.; Hamzavi, J.; Gressner, A.M.; Thorikay, M.; ten Dijke, P.; Mertens, P.R.; Breitkopf, K.; et al. Id1 is a critical mediator in TGF- $\beta$-induced transdifferentiation of rat hepatic stellate cells. Hepatology 2006, 43, 1032-1041.

32. Panchenko, M.P.; Williams, M.C.; Brody, J.S.; Yu, Q. Type I receptor serine-threonine kinase preferentially expressed in pulmonary blood vessels. Am. J. Physiol. 1996, 270, L547-L558.

33. Gonzalez-Nunez, M.; Munoz-Felix, J.M.; Lopez-Novoa, J.M. The ALK-1/Smad1 pathway in cardiovascular physiopathology. A new target for therapy? Biochim. Biophys. Acta 2013, 1832, 1492-1510.

34. Upton, P.D.; Davies, R.J.; Trembath, R.C.; Morrell, N.W. Bone morphogenetic protein (BMP) and activin type II receptors balance BMP9 signals mediated by activin receptor-like kinase-1 in human pulmonary artery endothelial cells. J. Biol. Chem. 2009, 284, 15794-15804.

35. Star, G.P.; Giovinazzo, M.; Langleben, D. Bone morphogenic protein-9 stimulates endothelin-1 release from human pulmonary microvascular endothelial cells: A potential mechanism for elevated ET-1 levels in pulmonary arterial hypertension. Microvasc. Res. 2010, 80, 349-354.

36. Xu, D.J.; Zhao, Y.Z.; Wang, J.; He, J.W.; Weng, Y.G.; Luo, J.Y. Smads, p38 and ERK1/2 are involved in BMP9-induced osteogenic differentiation of C3H10T1/2 mesenchymal stem cells. BMB Rep. 2012, 45, 247-252. 
37. Zhao, Y.F.; Xu, J.; Wang, W.J.; Wang, J.; He, J.W.; Li, L.; Dong, Q.; Xiao, Y.; Duan, X.L.; Yang, X.; et al. Activation of JNKs is essential for BMP9-induced osteogenic differentiation of mesenchymal stem cells. BMB Rep. 2013, 46, 422-427.

38. Zhao, Y.; Song, T.; Wang, W.; Wang, J.; He, J.; Wu, N.; Tang, M.; He, B.; Luo, J. P38 and ERK1/2 MAPKs act in opposition to regulate BMP9-induced osteogenic differentiation of mesenchymal progenitor cells. PLoS One 2012, 7, e43383.

39. Munoz-Felix, J.M.; Gonzalez-Nunez, M.; Lopez-Novoa, J.M. ALK1-Smad1/5 signaling pathway in fibrosis development: Friend or foe? Cytokine Growth Factor Rev. 2013, 24, 523-537.

40. Shen, H.; Fan, J.; Burczynski, F.; Minuk, G.Y.; Cattini, P.; Gong, Y. Increased Smad1 expression and transcriptional activity enhances trans-differentiation of hepatic stellate cells. J. Cell. Physiol. 2007, 212, 764-770.

41. Pannu, J.; Nakerakanti, S.; Smith, E.; ten Dijke, P.; Trojanowska, M. Transforming growth factor- $\beta$ receptor type I-dependent fibrogenic gene program is mediated via activation of Smad 1 and ERK1/2 pathways. J. Biol. Chem. 2007, 282, 10405-10413.

42. Beger, B.; Robertson, K.; Evans, A.; Grant, A.; Berg, J. Expression of endoglin and the activin receptor-like kinase 1 in skin suggests a role for these receptors in normal skin function and skin tumorigenesis. Br. J. Dermatol. 2006, 154, 379-382.

43. Li, L.; Zhao, X.Y.; Wang, B.E. Down-regulation of transforming growth factor $\beta 1 /$ activin receptor-like kinase 1 pathway gene expression by herbal compound 861 is related to deactivation of LX-2 cells. World J. Gastroenterol. 2008, 14, 2894-2899.

44. Wang, L.; Wang, B.E.; Wang, J.; Xiao, P.G.; Tan, X.H. Herbal compound 861 regulates mRNA expression of collagen synthesis- and degradation-related genes in human hepatic stellate cells. World J. Gastroenterol. 2008, 14, 1790-1794.

45. Kaimori, A.; Potter, J.; Kaimori, J.Y.; Wang, C.; Mezey, E.; Koteish, A. Transforming growth factor- $\beta 1$ induces an epithelial-to-mesenchymal transition state in mouse hepatocytes in vitro. J. Biol. Chem. 2007, 282, 22089-22101.

46. Bernabeu, C.; Lopez-Novoa, J.M.; Quintanilla, M. The emerging role of TGF- $\beta$ superfamily coreceptors in cancer. Biochim. Biophys. Acta 2009, 1792, 954-973.

47. Meurer, S.K.; Tihaa, L.; Borkham-Kamphorst. E.; Weiskirchen, R. Expression and functional analysis of endoglin in isolated liver cells and its involvement in fibrogenic Smad signalling. Cell Signal. 2011, 23, 683-699.

48. Guerrero-Esteo, M.; Sanchez-Elsner, T.; Letamendia, A.; Bernabeu, C. Extracellular and cytoplasmic domains of endoglin interact with the transforming growth factor- $\beta$ receptors I and II. J. Biol. Chem. 2002, 277, 29197-29209.

49. Koleva, R.I.; Conley, B.A.; Romero, D.; Riley, K.S.; Marto, J.A.; Lux, A.; Vary, C.P. Endoglin structure and function: Determinants of endoglin phosphorylation by transforming growth factor- $\beta$ receptors. J. Biol. Chem. 2006, 281, 25110-25123.

50. Finnson, K.W.; Philip, A. Endoglin in liver fibrosis. J. Cell Commun. Signal. 2012, 6, 1-4.

51. Finnson, K.W.; Parker, W.L.; Chi, Y.; Hoemann, C.D.; Goldring, M.B.; Antoniou, J.; Philip, A. Endoglin differentially regulates TGF- $\beta$-induced $\operatorname{Smad} 2 / 3$ and $\mathrm{Smad} 1 / 5$ signalling and its expression correlates with extracellular matrix production and cellular differentiation state in human chondrocytes. Osteoarthritis Cartilage 2010, 18, 1518-1527. 
52. Morris, E.; Chrobak, I.; Bujor, A.; Hant, F.; Mummery, C.; ten Dijke, P.; Trojanowska, M. Endoglin promotes TGF- $\beta /$ Smad1 signaling in scleroderma fibroblasts. J. Cell. Physiol. 2011, 226, 3340-3348.

53. Scherner, O.; Meurer, S.K.; Tihaa, L.; Gressner, A.M.; Weiskirchen, R. Endoglin differentially modulates antagonistic transforming growth factor- $\beta 1$ and BMP-7 signaling. J. Biol. Chem. 2007, 282, 13934-13943.

54. Clemente, M.; Nunez, O.; Lorente, R.; Rincon, D.; Matilla, A.; Salcedo, M.; Catalina, M.V.; Ripoll, C.; Iacono, O.L.; Banares, R.; et al. Increased intrahepatic and circulating levels of endoglin, a TGF- $\beta 1$ co-receptor, in patients with chronic hepatitis $\mathrm{C}$ virus infection: Relationship to histological and serum markers of hepatic fibrosis. J. Viral Hepat. 2006, 13, 625-632.

55. Preativatanyou, K.; Honsawek, S.; Chongsrisawat, V.; Vejchapipat, P.; Theamboonlers, A.; Poovorawan, Y. Correlation of circulating endoglin with clinical outcome in biliary atresia. Eur. J. Pediatr. Surg. 2010, 20, 237-241.

56. Meurer, S.K.; Alsamman, M.; Sahin, H.; Wasmuth, H.E.; Kisseleva, T.; Brenner, D.A.; Trautwein, C.; Weiskirchen, R.; Scholten, D. Overexpression of endoglin modulates TGF- $\beta 1$-signalling pathways in a novel immortalized mouse hepatic stellate cell line. PLoS One 2013, 8, e56116.

57. Herrera, B.; Garcia-Alvaro, M.; Cruz, S.; Walsh, P.; Fernandez, M.; Roncero, C.; Fabregat, I.; Sanchez, A.; Inman, G.J. BMP9 is a proliferative and survival factor for human hepatocellular carcinoma cells. PLoS One 2013, 8, e69535.

58. Li, M.X.; Liu, B.C. Epithelial to mesenchymal transition in the progression of tubulointerstitial fibrosis. Chin. Med. J. 2007, 120, 1925-1930.

59. Ding, B.S.; Cao, Z.; Lis, R.; Nolan, D.J.; Guo, P.; Simons, M.; Penfold, M.E.; Shido, K.; Rabbany, S.Y.; Rafii, S. Divergent angiocrine signals from vascular niche balance liver regeneration and fibrosis. Nature 2014, 505, 97-102.

60. Matsuda, Y.; Yamagiwa, S.; Takamura, M.; Honda, Y.; Ishimoto, Y.; Ichida, T.; Aoyagi, Y. Overexpressed Id-1 is associated with a high risk of hepatocellular carcinoma development in patients with cirrhosis without transcriptional repression of p16. Cancer 2005, 104, 1037-1044.

61. Vincent, K.J.; Jones, E.; Arthur, M.J.; Smart, D.E.; Trim, J.; Wright, M.C.; Mann, D.A. Regulation of E-box DNA binding during in vivo and in vitro activation of rat and human hepatic stellate cells. Gut 2001, 49, 713-719.

62. Abu Rajab, M.; Guerin, L.; Lee, P.; Brown, K.E. Iron overload secondary to cirrhosis: A mimic of hereditary haemochromatosis? Histopathology 2014, 65, 561-569.

63. Costa-Matos, L.; Batista, P.; Monteiro, N.; Simoes, M.; Egas, C.; Pereira, J.; Pinho, H.; Santos, N.; Ribeiro, J.; Cipriano, M.A.; et al. Liver hepcidin mRNA expression is inappropriately low in alcoholic patients compared with healthy controls. Eur. J. Gastroenterol. Hepatol. 2012, 24, $1158-1165$.

64. Horl, W.H.; Schmidt, A. Low hepcidin triggers hepatic iron accumulation in patients with hepatitis C. Nephrol. Dial. Transplant. 2014, 29, 1141-1144.

65. Fujita, N.; Horiike, S.; Sugimoto, R.; Tanaka, H.; Iwasa, M.; Kobayashi, Y.; Hasegawa, K.; Ma, N.; Kawanishi, S.; Adachi, Y.; et al. Hepatic oxidative DNA damage correlates with iron overload in chronic hepatitis C patients. Free Radic. Biol. Med. 2007, 42, 353-362. 
66. Zhao, J.Y.; Li, Y.W.; Li, L. The role of iron and hepcidin in hepatic fibrosis. Prog. Physiol. 2010, 41, 183-188.

67. Nagashima, M.; Kudo, M.; Chung, H.; Ishikawa, E.; Hagiwara, S.; Nakatani, T.; Dote, K. Regulatory failure of serum prohepcidin levels in patients with hepatitis C. Hepatol. Res. 2006, 36, 288-293.

68. Fujita, N.; Sugimoto, R.; Takeo, M.; Urawa, N.; Mifuji, R.; Tanaka, H.; Kobayashi, Y.; Iwasa, M.; Watanabe, S.; Adachi, Y.; et al. Hepcidin expression in the liver: Relatively low level in patients with chronic hepatitis C. Mol. Med. 2007, 13, 97-104.

69. Tanno, T.; Bhanu, N.V.; Oneal, P.A.; Goh, S.H.; Staker, P.; Lee, Y.T.; Moroney, J.W.; Reed, C.H.; Luban, N.L.; Wang, R.H.; et al. High levels of GDF15 in thalassemia suppress expression of the iron regulatory protein hepcidin. Nat. Med. 2007, 13, 1096-1101.

70. Sebastiani, G.; Gkouvatsos, K.; Maffettone, C.; Busatto, G.; Guido, M.; Pantopoulos, K. Accelerated $\mathrm{CCl}_{4}$-induced liver fibrosis in $\mathrm{Hjv}^{-/-}$mice, associated with an oxidative burst and precocious profibrogenic gene expression. PLoS One 2011, 6, e25138.

71. Gordillo-Bastidas, D.; Oceguera-Contreras, E.; Salazar-Montes, A.; Gonzalez-Cuevas, J.; Hernandez-Ortega, L.D.; Armendariz-Borunda, J. Nrf2 and Snail-1 in the prevention of experimental liver fibrosis by caffeine. World J. Gastroenterol. 2013, 19, 9020-9033.

72. Bi, W.R.; Jin, C.X.; Xu, G.T.; Yang, C.Q. Bone morphogenetic protein-7 regulates Snail signaling in carbon tetrachloride-induced fibrosis in the rat liver. Exp. Ther. Med. 2012, 4, 1022-1026.

(C) 2014 by the authors; licensee MDPI, Basel, Switzerland. This article is an open access article distributed under the terms and conditions of the Creative Commons Attribution license (http://creativecommons.org/licenses/by/4.0/). 